\title{
Mechanical Characteristics and Failure Characteristics of Jointed Rock under Axial Unloading and Radial Unloading
}

\author{
Tielin Han $\mathbb{D}^{1},{ }^{1,2,3}$ Junping Shi, ${ }^{1,3}$ and Yunsheng Chen ${ }^{1,3}$ \\ ${ }^{1}$ State Key Laboratory of Eco-Hydraulics in Northwest Arid Region, Xi'an University of Technology, Shaanxi, Xi'an 710048, China \\ ${ }^{2}$ Guangdong Provincial Key Laboratory of Durability for Marine Civil Engineering, \\ College of Civil and Transportation Engineering, Shenzhen University, Shenzhen 518060, China \\ ${ }^{3}$ State Key Laboratory Base of Eco-Hydraulic Engineering in Arid Area, Xi'an University of Technology, Xi'an, Shaanxi, China \\ Correspondence should be addressed to Tielin Han; s3050210133@163.com
}

Received 14 May 2020; Accepted 2 July 2020; Published 25 July 2020

Academic Editor: Chunshun Zhang

Copyright (C) 2020 Tielin Han et al. This is an open access article distributed under the Creative Commons Attribution License, which permits unrestricted use, distribution, and reproduction in any medium, provided the original work is properly cited.

\begin{abstract}
In this research, we used precracked rock-like materials (simulating jointed rock masses) to assess the triaxial compression of cracked specimens under axial unloading and radial unloading paths. The research goal was to comparatively analyze and research the mechanical characteristics of cracked specimens to ascertain how deformation properties, strength properties, and failure features influence the overall mechanisms in context. The test results showed that the failure of specimens did not appear at peak stress under axial unloading and radial unloading. The elastic stage, yield stage, and failure stage of the stress-strain curves were not clearly defined in the testing process. However, the stress drop and the strain of resilience of the lateral strain-axial strain curve happened under this path because the lateral strain was significantly greater than the axial strain. This in turn led the volumetric strain to remain in a state of expansion throughout the testing process. The mechanical properties under this path are mainly influenced by the crack inclination angle, the unloading speed of radial pressure, and the initial confining pressure. However, there is a difference in the influence of these three factors on their mechanical parameters; that is, the influence of the crack inclination angle is the greatest, followed by that of the initial confining pressure, while that of the unloading speed of radial pressure is relatively small. Finally, the failure characteristics of specimens often present mixed tension-shear failure under axial unloading and radial unloading.
\end{abstract}

\section{Introduction}

The unloading of rock mass and the accompanying release of in situ stress is part of the excavation of rock masses, which is often part of the construction process in rock-mass engineering. However, there are significant differences in the mechanical parameters, failure properties, and its mechanisms of rock in unloading conditions compared to those same factors under loading conditions. Furthermore, unloading damage is a phenomenon inherent to excavation of rock mass engineering, although it exists to varying degrees depending on the situation. A number of scholars have pointed out that the mechanics of unloading rock mass are more closely in accord with the mechanics state of actual engineering than that of loading rock mass. Therefore, the deformation, mechanical, and failure properties comprise one of the important research subjects in the current research field of rock mechanics under unloading conditions.

In order to explore the mechanical properties of the excavation of rock masses under unloading conditions in engineering, many scholars have begun to simulate the excavation of rock masses through triaxial indoor experiments and physical model tests under unloading conditions. There are successful studies on the effects of unloading paths on rock conducted by scholars. Jaeger [1] pointed out that the relationship between rock strength and stress path was a problem yet to be discussed. Shimamoto [2] presented a new method for measuring frictional strength over a wide range of normal stress levels under confining pressure reduction experiments. The mechanical characteristics of rock after 
unloading had obvious deterioration trend by Gao et al. [3] and $\mathrm{Hu}$ et al. [4]. Lau and Chandler [5] developed three laboratory test techniques to study and quantify damage development in loaded rock specimens and they also pointed out that load test paths do not align with those used in standard engineering practice; and it is more accurate to say that the mechanical parameters of rock were determined via unloading test paths. Hudson et al. [6] and Martin [7] studied the influence of unloading conditions on the mechanical properties of rock both below and above the stress level of the elastic limit with the theory that the influence of both the loading system and boundary conditions on both deformation process and the mechanical properties was below the elastic limit.

In addition, the stress path not only affects the rock strength, but also has certain influence on its failure characteristics. But in the early stages of the development of rock mechanics, some scholars thought that the influence of stress paths on the failure process is not obvious $[8,9]$. Wu and $\mathrm{Li}$ [10] came to the same conclusions as Swanson and Crouch, and they also found that the effect of stress paths on the deformation property was obvious. However, scholars gradually elucidated the influence of stress paths on the rock failure process with the improvement of test equipment and test methods, with many useful results. Wang et al. [11, 12], $\mathrm{Du}$ et al. [13], and Meng et al. [14, 15] studied failure properties of cubic granite, marble, and sandstone specimens under true triaxial stress and under high uniaxial stress; Li and Wang [16] and Chen et al. [17] studied the failure characteristics of rock under three stress paths and found that there were relationships between strength characteristics, volume expansion, and stress paths. Kaiser et al. [18] presented a practical example to illustrate the usefulness of stress change measurements in providing an accurate picture of mining-induced stress changes and their value for numerical model calibration. Wu et al. [19] found that the yield criterion of the Mohr-Coulomb test was not suited to analyze the failure of rock mass under unloading conditions. Excavation of a circular test tunnel in massive stretches of brittle rock resulted in failure around the tunnel engineering, and the back-calculated strength for the failed rock around the tunnel is approximately one-half of that measured in laboratory tests. Therefore, a better understanding of destruction related to excavation under unloading conditions is important for the prediction of rock bursts and other problems.

To reveal the failure mechanism of rocks under unloading conditions, many scholars also have studied the damage characteristics of rocks under the unloading paths, with many useful results. You and Hua [20] explored the relationship between rock strength, weakness, and destruction in order to propose a softening modulus of material to describe the degradation of rock strength. Taheri and Tani [21] used computed tomography to analyze the damage sustained by rock under unloading conditions, and they concluded that the unloading destruction process could be divided into five stages: cracks appearing; bifurcation; development; cracks gathering; and sudden destruction. In contrast, Corkum and Martin [22] found that the response to excavation unloading conditions is nonlinear and should be determined using unloading experiments. Tsai et al. [23] analyzed the stress threshold for damage to sandstone and gave the plastic potential surface under different stress paths. Hua and You [24] analyzed the source of release energy during the rock damage process under unloading conditions and pointed out that elastic energy, stored before unloading conditions were present, was enough to cause rock damage.

The constitutive model of rock is at the core of rock mechanics research. Currently, the constitutive relationship for rock under loading conditions is the relationship between stress and strain. However, the excavation that takes place is not a loading process during actual engineering, and the relationship between stress and strain of rock is different under unloading conditions. Li et al. [25] adopted the weakening rule of deformation modulus under loading and unloading conditions and based their work on the Weng Model; they established a constitutive model for marble under loading and unloading conditions by introducing coefficient $R$. Guo et al. [26] studied variation law of coal permeability under cyclic loading and unloading. Gaziev $[27,28]$ proposed a method for assessing cracked stress damage after considering the influence on three stress paths by analyzing the stress state of the rock. Cai et al. [29, 30] established a nonlinear elastic constitutive model for joint rock by considering the influence of excavation unloading conditions and applied it to analyze the mechanical properties of the surrounding rock of tunnels. Wu and Zhang [31] established a constitutive model of rock by defining a disturbance function based on the disturbed state concept theory; this could reflect characteristic unloading damage in rock. The micromechanical damage mechanics formula has been shown to give an adequate description of the triaxial failure surface for a wide variety of rocks at low levels of confining pressure [32]. Bhat et al. [33] thought the nonlinearity in the failure surface and stress-strain curves observed in triaxial experiments on Westerly granite at low loading rates was probably due to the damage mechanics.

Rock failure is closely related to rock fracture. Research on the fracture damage mechanism in rock was studied as part of the overall process of rock, from the initiation of micro cracks, expansion, and evolution toward the formation of macroscopic cracks, and finally to the fracture and failure process. Many scholars studied fracture damage mechanics under loading conditions extensively, such as [34], Reyes and Einstein [35], and Nolen-Hook and Gordon [36]. In addition, James et al. [37] studied the fracture mechanism using three-dimensional numerical models to simulate the closed crack process under circulation and uninstall conditions. Han et al. [38] found that the unloading mechanical characteristics of cracked specimens are mainly related to the crack angles, the loading paths, and the initial confining pressures. The factor with the greatest influence was the crack angle, while the confining pressure unloading rate held an intermediate level of influence and the initial confining pressure was least influential. However, the mechanical properties of rock under axial unloading and radial unloading conditions are rarely studied, especially for cracked rock. Therefore, it is necessary to further 
experimentally study the mechanical prosperities of cracked rock under axial unloading and radial unloading paths.

This study conducted triaxial compression experiments on cracked rock specimens under axial unloading and radial unloading paths. The variation regularities in the mechanical properties (such as deformation properties and strength properties) and failure properties of cracked rock under this stress path were analyzed along with their mechanisms. This study can serve as a reference for the engineering of rock masses in the design and construction phase.

\section{Test Instrument and Specimen Preparation}

The large-scale multi-functional material test machine was used in the experiment (Figure 1). This testing machine is composed of five parts: axial loading system, confining pressure loading system, horizontal shearing system, acoustic wave detection system, and computer control and measurement system. The maximum axial stress was $1500 \mathrm{kN}$; the maximum confining pressure was $80 \mathrm{MPa}$; and the measurement ranges for axial and radial deformation were $0-10 \%$ and $0-5 \%$, respectively.

The authors used prefabricated cracked rock-like materials to simulate jointed rock masses including different cracked inclination angles. The ratio of $c$ (cement), $s$ (sand), and $w$ (water) used $(c: s: w)$ was $1: 2: 0.5$. The authors used P.O. 32.5R ordinary Portland cement and standard sand, and by using cement mortar materials and embedding copper sheets to simulate jointed cracked rock, the cracks were prefabricated in the center of the mortar specimens according to the design of the crack length and angle. The thickness of the copper is $0.3 \mathrm{~mm}$, and its width is $2 \mathrm{~cm}$ (as shown in Figure 2). The copper was removed after 12 hours when the mortar specimen was initially set. The authors removed the mold after 24 hours and then put the specimens into the standard curing box until 28 days had elapsed. The specimens were then processed into cylinders specimens of $50 \mathrm{~mm}$ diameter and $100 \mathrm{~mm}$ length.

The mechanical behaviors and failure characteristics of cracked mortar specimens under different axial unloading and radial unloading paths were investigated in this paper.

Before the test, the specimens were dried at $105^{\circ} \mathrm{C}$ to maintain a constant weight and then cooled for mass measuring. Later, the discrete-type specimens were screened using acoustic testing, and specimens were grouped based on P-wave velocity. A total of 54 cracked specimens were selected and divided into 9 groups. The cracked inclination angle was set to $0^{\circ}, 30^{\circ}, 45^{\circ}, 60^{\circ}$, and $90^{\circ}$, and four tests were conducted in parallel under each condition and average triaxial mechanical parameters were regarded as a final result.

\section{Experimental Method}

Firstly, confining pressure was increased to the set test value at a rate of $0.1 \mathrm{MPa} / \mathrm{s}$, and then axial compression was increased to the set test value at a rate of $0.2 \mathrm{~mm} / \mathrm{min}$. When axial pressure and confining pressure were increased to these values, axial pressure was unloaded at a rate of $0.1 \mathrm{~mm} / \mathrm{min}$; meanwhile, confining pressure was unloaded at a certain rate until specimens showed damage.

The main research focuses were as follows. (1) The influence of crack inclination angles, that is, $0^{\circ}, 30^{\circ}, 45^{\circ}, 60^{\circ}$, and $90^{\circ}$, on the mechanical properties of specimens under $15 \mathrm{MPa}$ initial confining pressure, at $0.5 \mathrm{MPa} / \mathrm{s}$ unloading rate of confining pressure, and $60 \mathrm{MPa}$ axial pressure. (2) The influence of initial confining pressures, that is, 8, 10, and $15 \mathrm{MPa}$, on the mechanical properties under $60 \mathrm{MPa}$ initial axial pressure, and at $0.5 \mathrm{MPa} / \mathrm{s}$ unloading rate of confining pressure, on the $45^{\circ} \mathrm{crack}$ inclination angle. (3) The influence of confining pressure unloading rates, that is, $0.1,0.5$, and $1.0 \mathrm{MPa} / \mathrm{s}$, on the mechanical properties under $60 \mathrm{MPa}$ initial axial pressure, and $15 \mathrm{MPa}$ initial confining pressure, on the $45^{\circ}$ crack inclination angle. The detailed test plan is shown in Table 1.

\section{Stress-Strain Curve}

The $\left(\sigma_{1}-\sigma_{3}\right)-\varepsilon_{1}$ curves of specimens under axial unloading and radial unloading conditions are shown in Figure 3. Figure 3 indicates that there are significant differences in stress-strain curves under axial unloading and radial unloading, and loading paths. The elastic stage, yield stage, and failure stage of stress-strain curves did not present clearly in the testing process. The stress drop of the $\left(\sigma_{1}-\right.$ $\left.\sigma_{3}\right)-\varepsilon_{1}$ curve was observed under axial unloading and radial unloading conditions, but the resilience phenomenon was not obvious. The attenuation rate of stress reduced after entering into the damage stage. However, the stress drop and strain of resilience of the lateral strain-axial strain curve happened under axial unloading and radial unloading conditions because the lateral strain was significantly greater than the axial strain of the specimens. This led to the volumetric strain of specimens which remained in a state of expansion during the testing process. The other phases of the $\left(\sigma_{1}-\sigma_{3}\right)-\varepsilon_{1}$ curves were observed to be in an approximately linear relationship; the failure process proceeded smoothly without the phenomenon of an apparent stress drop.

Effect of crack inclination angle: Figure 3(a) indicates that the stress-strain curves were almost the same for the different crack inclination angles. The main differences existed in the significant stress drop of specimens at the initial test stage. The peak strain was highest at the $30^{\circ} \mathrm{crack}$ inclination angle; it was lowest at $90^{\circ}$; at $45^{\circ}, 60^{\circ}$, and $0^{\circ}$, it was in the middle.

Effect of confining pressure unloading rate: the $\left(\sigma_{1}-\right.$ $\left.\sigma_{3}\right)-\varepsilon_{1}$ curves of cracked specimens under different confining pressure unloading rates are shown in Figure 3(b). Figure 3(b) indicates that the stress-strain curves are basically the same under different confining pressure unloading rates; in addition to the drops in stress and strain resilience observed in the stress-strain curve in the initial test stage, there was a linear relationship in the stress-strain curves, and the failure process was relatively stable.

Differences existed in the stress-strain curves of cracked specimens during the initial test stage and the failure stage. Figure 3(b) indicates that significant drops in stress and 


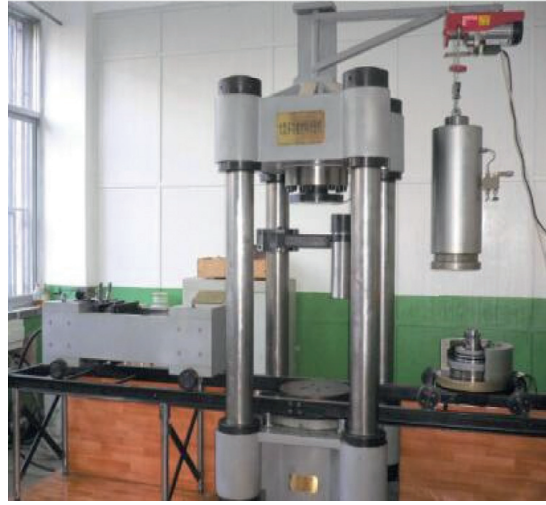

(a)

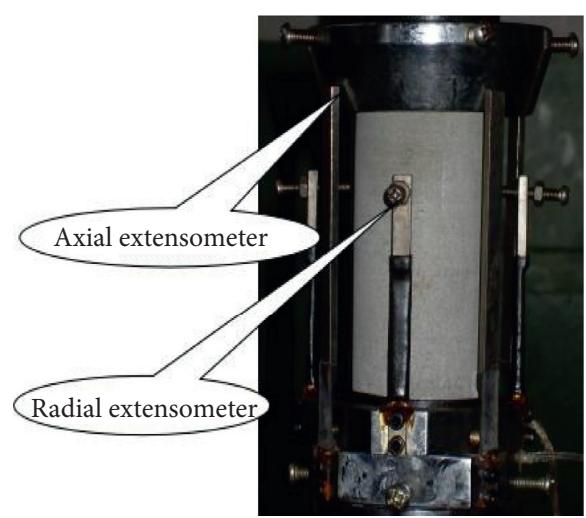

(b)

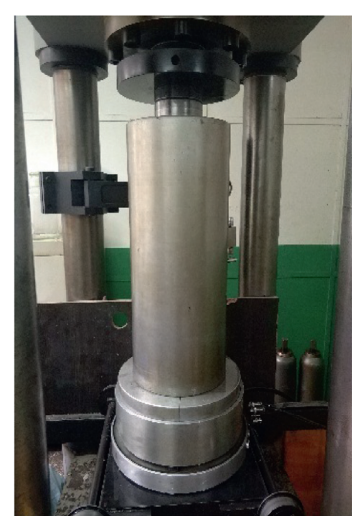

(c)

FIgURE 1: The WDT-1500 multi-function material testing machine, extensometer diagram, pressure chamber diagram. (a) Testing machine. (b) Extensometer diagram. (c) Pressure chamber diagram.

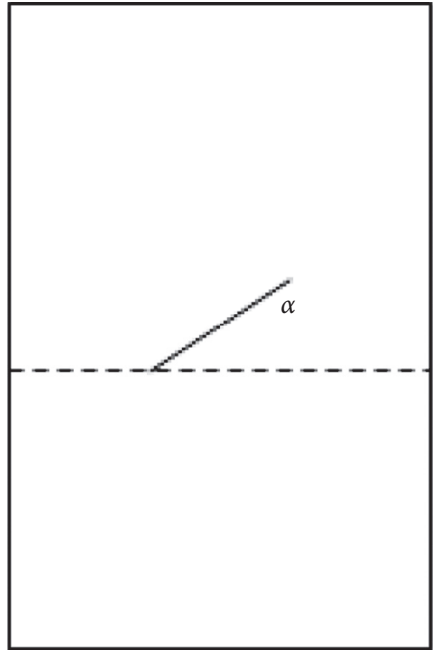

(a)

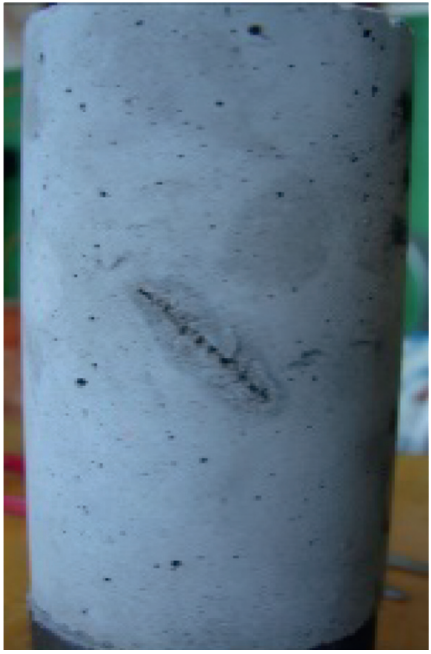

(b)

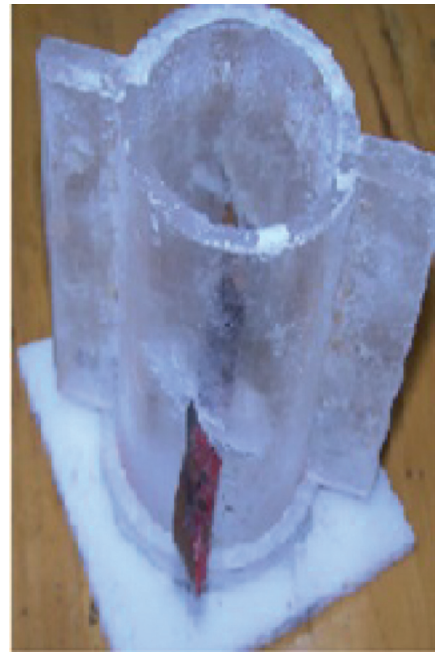

(c)

FIGURE 2: Sketch map of molding tool and cracked specimens.

strain resilience in the stress-strain curve happened during the initial test stage. As the test continued, because the lateral strain increased at a greater rate than did the axial strain, the result was the obvious strain resilience of the stress-strain curves. Meanwhile, as the confining pressure unloading rate decreased, a more obvious stress drop and resilience phenomenon was observed. There was a linear relationship in the stress-strain curve during the failure stage; this suggested that the increasing rate of lateral strain reduced and was then basically equal to that of the axial strain. Meanwhile, as the confining pressure unloading rate increased, the decay rate of stress also increased, as did the damage rate of specimens.

Effect of initial confining pressure: Figure 3(c) indicates that the stress-strain curves were almost the same under different initial confining pressure levels at the initial test stage. The influence of initial confining pressure on deformation properties of specimens was not obvious; however, differences in the stress-strain curves existed at the damage stage under different initial confining pressure levels.
Specifically, the lower the initial confining pressure, the greater the decay rate of stress with strain and, meanwhile, the faster the damage rate of cracked specimens.

\section{Lateral Strain-Axial Strain Curve}

The lateral strain-axial strain curves of specimens under axial unloading and radial unloading conditions are shown in Figure 4.

Figure 4 reveals an obvious resilience in the lateral strainaxial strain curves during the initial test stage; the increase rate of the lateral strain was significantly greater than that of the axial strain; this led to the obvious resilience of stressstrain happening. As the test continued, the increase rate of lateral deformation decreased gradually. There was a linear relationship between the lateral strain and axial strain in the damage stage and the slope of the lateral strain-axial strain decreased. The lateral strain of specimens remained in the expansion state throughout the entire testing process. 
TABLE 1: Test project of cracked specimens under different axial unloading and radial unloading paths.

\begin{tabular}{|c|c|c|c|c|c|}
\hline Unloading conditions & $\begin{array}{c}\text { Cracked } \\
\text { inclination angle } \\
\left({ }^{\circ}\right)\end{array}$ & $\begin{array}{c}\text { Initial axial } \\
\text { pressure }(\mathrm{MPa})\end{array}$ & $\begin{array}{l}\text { Initial confining } \\
\text { pressure }(\mathrm{MPa})\end{array}$ & $\begin{array}{c}\text { Confining pressure } \\
\text { unloading rate }(\mathrm{MPa} / \mathrm{s})\end{array}$ & $\begin{array}{c}\text { Axial pressure } \\
\text { unloading rate } \\
(\mathrm{mm} / \mathrm{min})\end{array}$ \\
\hline \multirow{9}{*}{$\begin{array}{l}\text { Axial unloading and } \\
\text { radial unloading path }\end{array}$} & 0 & 60 & 15 & 0.5 & 0.1 \\
\hline & 30 & 60 & 15 & 0.5 & 0.1 \\
\hline & 45 & 60 & 15 & 0.5 & 0.1 \\
\hline & 60 & 60 & 15 & 0.5 & 0.1 \\
\hline & 90 & 60 & 15 & 0.5 & 0.1 \\
\hline & 45 & 60 & 15 & 0.1 & 0.1 \\
\hline & 45 & 60 & 15 & 1.0 & 0.1 \\
\hline & 45 & 60 & 10 & 0.5 & 0.1 \\
\hline & 45 & 60 & 8 & 0.5 & 0.1 \\
\hline
\end{tabular}

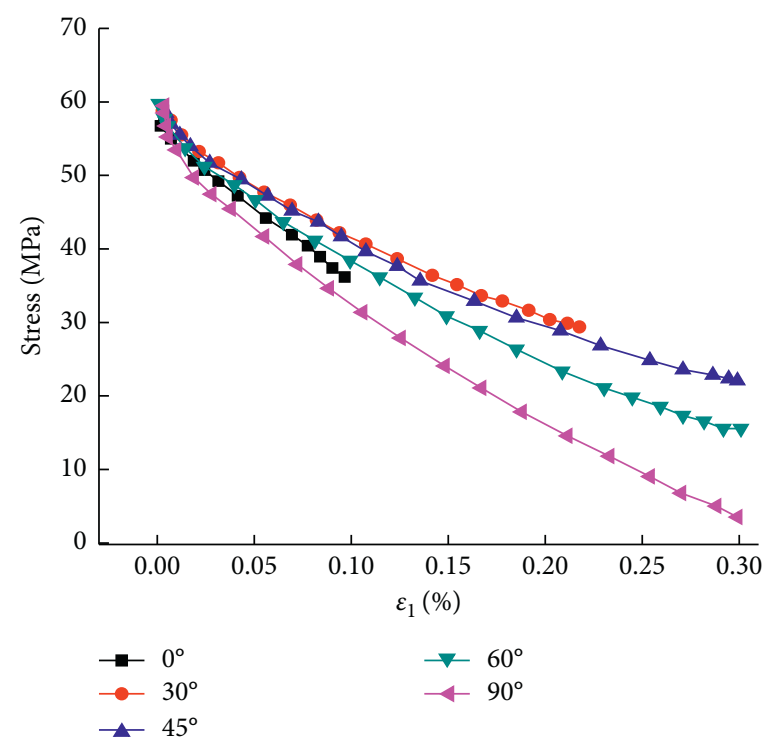

(a)

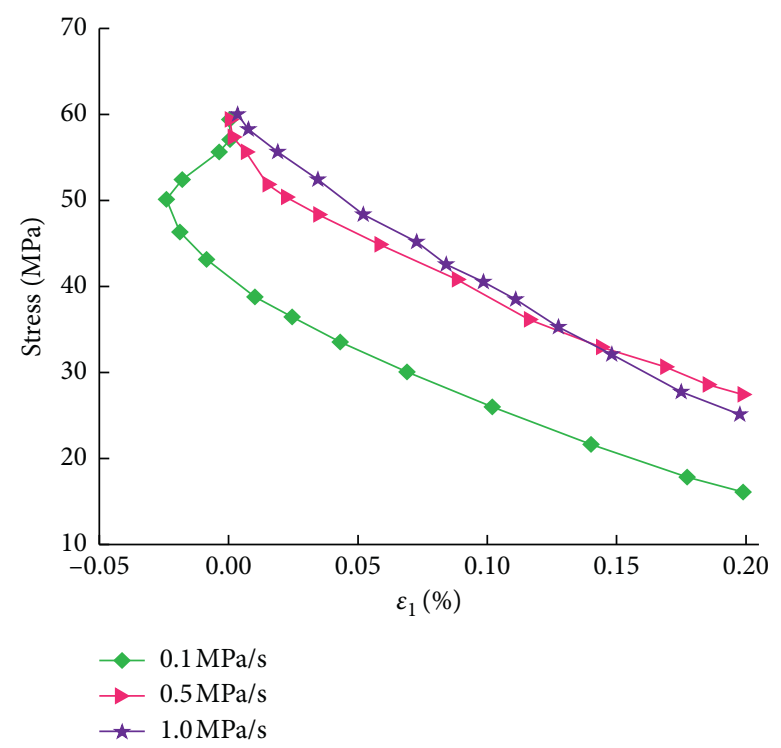

(b)

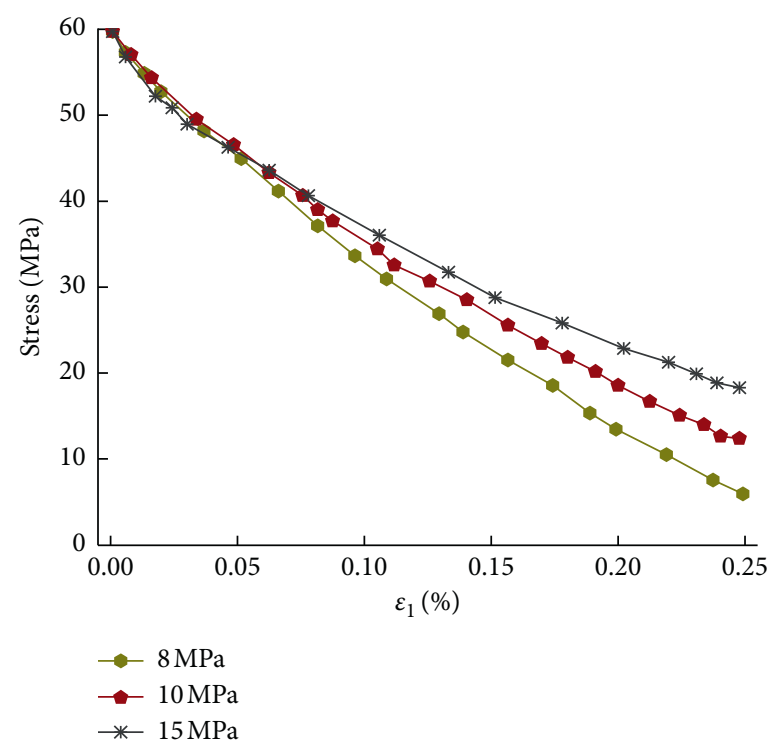

(c)

FiguRE 3: $\left(\sigma_{1}-\sigma_{3}\right)-\varepsilon_{1}$ curves of cracked specimens under axial unloading and radial unloading conditions. (a) Effect of crack angle. (b) Effect of unloading rate of confining pressure. (c) Effect of initial confining pressure. 


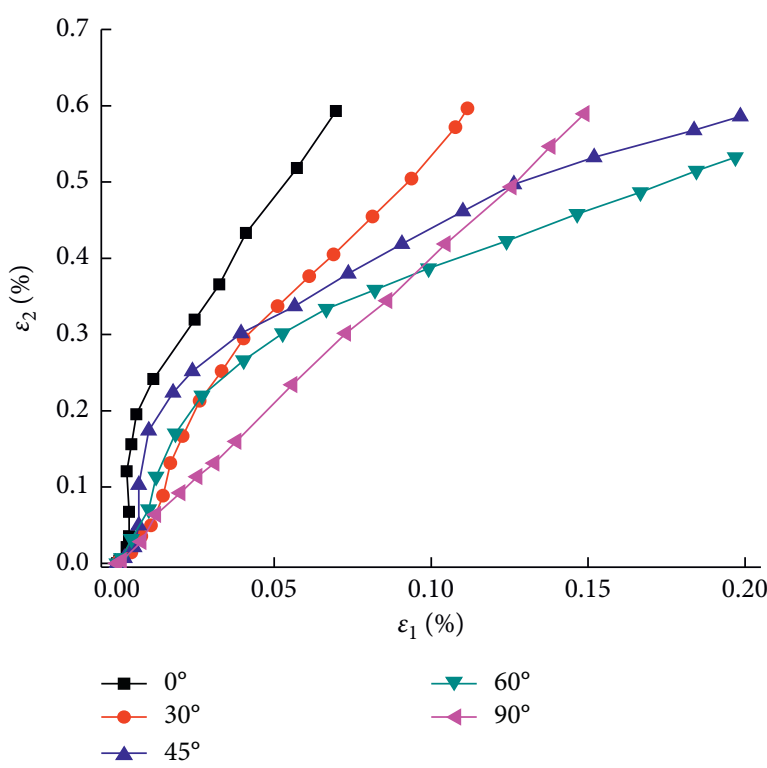

(a)

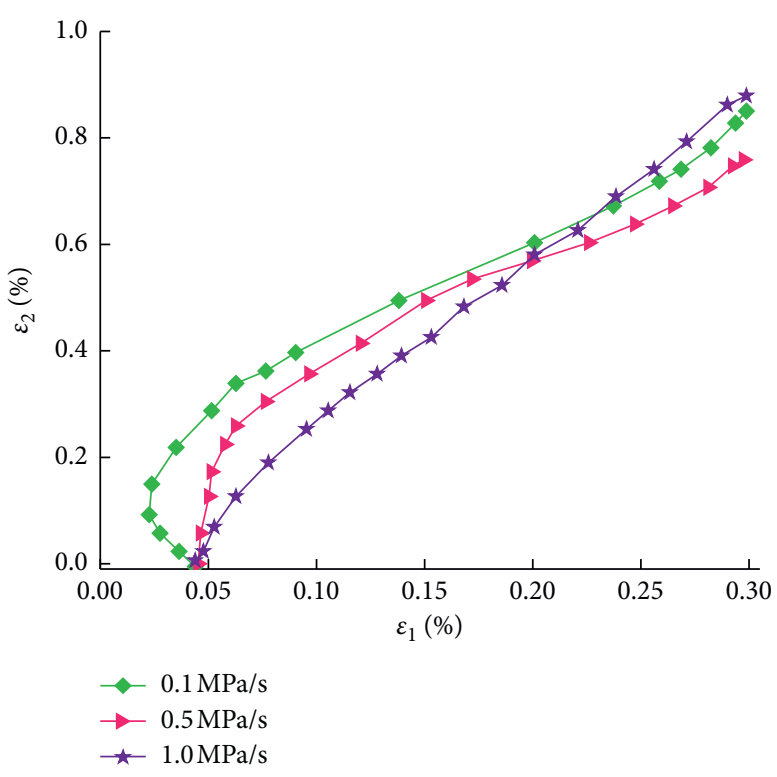

(b)

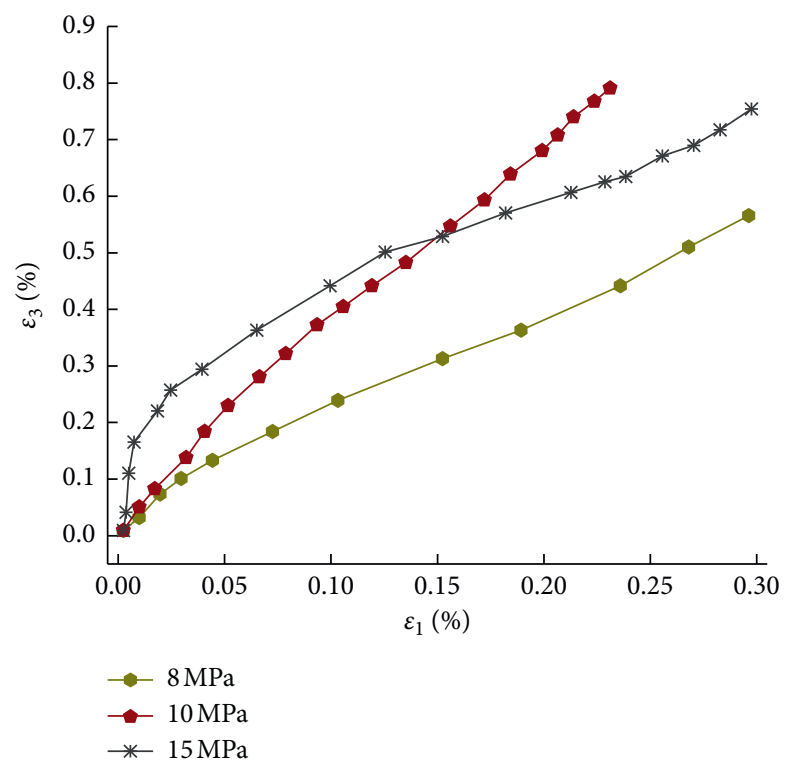

(c)

FIGURE 4: $\varepsilon_{3}-\varepsilon_{1}$ curves of cracked specimens under axial unloading and radial unloading conditions. (a) Effect of crack angle. (b) Effect of unloading rate of confining pressure. (c) Effect of initial confining pressure.

Effect of crack inclination angle: different crack inclination angles of $\varepsilon_{3}-\varepsilon_{1}$ curves of specimens under axial unloading and radial unloading conditions are shown in Figure 4(a). Figure 4(a) indicates that there was a small amount of resilient axial strain at the $30^{\circ}$ crack inclination angle before the damage occurred. During the failure stage, the slope of the $\varepsilon_{3}-\varepsilon_{1}$ curves was the greatest at the $0^{\circ}$ crack inclination angle. Furthermore, the increasing rate of lateral deformation was the fastest at the $0^{\circ}$ crack inclination angle and was the slowest at the $45^{\circ}$ crack inclination angle.

Effect of confining pressure unloading rate: different confining pressure unloading rates of $\varepsilon_{3}-\varepsilon_{1}$ curves of specimens under axial unloading and radial unloading conditions are shown in Figure 4(b). Figure 4(b) indicates that when the initial axial pressure and initial confining pressure are kept constant, there is a direct relationship between the confining pressure unloading rate before the damage and the resilient axial strain. During the failure stage, the slower the confining pressure unloading rate, the smaller the slope of the $\varepsilon_{3}-\varepsilon_{1}$ curves, and the more fully developed the lateral deformation.

Effect of initial confining pressure: different initial confining pressures of $\varepsilon_{3}-\varepsilon_{1}$ curves of specimens under axial unloading and radial unloading conditions are shown in Figure 4(c). Figure 4(c) indicates that when initial axial pressure and confining pressure unloading rates were kept 
constant, the higher the initial confining pressure rate before the damage, the greater the slope of the $\varepsilon_{3}-\varepsilon_{1}$ curves, and the faster the development of lateral deformation. During the failure stage, with the loss of the initial confining pressure, the lateral deformation had a tendency to slow down.

\section{Stress-Volume Strain Curve}

The damage law evolution of rock is closely related to its volume expansion deformation in the process of unloading failure. The volumetric strain of rock is calculated according to the following formula:

$$
\varepsilon_{v}=\varepsilon_{1}+2 \varepsilon_{3},
$$

where $\varepsilon_{v}, \varepsilon_{1}$, and $\varepsilon_{3}$ are volume strain, axial strain, and lateral strain, respectively.

The stress-volume strain curves of specimens under axial unloading and radial unloading conditions are shown in Figure 5. Figure 5 indicates that the volume strain of cracked specimens remains in a state of expansion throughout the testing process under axial unloading and radial unloading conditions.

Effect of crack inclination angle: Figure 5(a) indicates that the stress-volume strain curves were almost the same despite different crack inclination angles, which illustrates that the influence of crack inclination angle on the stressvolume strain curves was not obvious. The main differences existed in the rate of volumetric expansion of specimens. The rate of volumetric expansion was smallest at the $90^{\circ} \mathrm{crack}$ inclination angle; the rate ranked in the middle for crack inclination angles of $30^{\circ}, 45^{\circ}$, and $60^{\circ}$; and the rate of volumetric expansion was fastest at the crack inclination angle of $90^{\circ}$.

Effect of confining pressure unloading rate: Figure 5(b) indicates that the stress-volume strain curves were almost the same despite different confining pressure unloading rates. There were significant stress drops and strain resilience in the stress-volume strain curves during the initial test stage. The more the confining pressure unloading rate increased, the less influence it had on the volume strain of specimens, and the less obvious the stress drop and strain resilience were. The results also showed that the more the confining pressure unloading rate decreased as other conditions remained unchanged, the greater the volume expansion rate of specimens was.

Effect of initial confining pressure: Figure 5(c) indicates that the stress-volume strain curves of the cracked specimens were almost the same despite different initial confining pressure during the initial stage. This illustrates that the influence of the initial confining pressure on the volume strain was not obvious. However, obvious differences existed in the stress-volume strain curves during the failure stage at different initial confining pressure. The greater the initial confining pressure, the greater the volume expansion rate of the cracked specimens.

After comparison and analysis, there were obvious differences in the deformation characteristics under the axial unloading and radial unloading conditions, and the three different stress paths [38]: axial loading and constant confining pressure, axial loading and radial unloading, and constant axial pressure and radial unloading. The elastic stage and yield stage of stressstrain of specimens were not obvious under axial unloading and radial unloading conditions. Significant stress drops and strain resilience of stress-strain curves were observed during the initial test stage, and the volumetric strain of specimens remained in a state of expansion throughout the testing process. However, the volume only began to expand during the yield stage under axial loading and radial unloading conditions; furthermore, volume expansion was observed during the failure stage under axial loading and constant confining pressure conditions.

\section{Strength Properties}

The $\left(\sigma_{1}-\sigma_{3}\right)-\sigma_{3}$ curves of specimens under axial unloading and radial unloading conditions are shown in Figure 6. Figure 6 indicates that peak strength was not observed when the cracked specimens were damaged under axial unloading and radial unloading conditions; however, the stress drop obviously occurred. To define strength when cracked specimens are damaged, the inflection point of the $\left(\sigma_{1}-\sigma_{3}\right)-\sigma_{3}$ curves was defined as the damage point when the stress level fell, and the stress of the inflection point was the peak strength of specimens. This was mainly because the cracked specimens, which had already broken, could not continue to bear the load. Figure 6 indicates that the inflection point was equal to the peak point of the conventional triaxial compression test; the significant stress drop occurred after this inflection point, and then the specimens entered into the damage stage.

The relationships among peak strength of specimens, different crack inclination angles, different confining pressure unloading rates, and different initial confining pressure rates under axial unloading and radial unloading conditions are shown in Figure 7 and Table 2. The peak strengths under the conventional triaxial compression tests [38] were greater than those observed under axial unloading and radial unloading conditions. Figure 7 (a) indicates that the peak strength of cracked specimens initially decreases and then increases with the continuous increase in the crack inclination angle. There are linear relationships among the peak strength, confining pressure unloading rate, and initial confining pressure. The greater the confining pressure unloading rate or the greater the initial confining pressure, the greater the peak strength of the specimens (as shown in Figures 7(b) $7(\mathrm{c}))$.

The peak strengths of specimens under axial unloading and radial unloading conditions are mainly influenced by crack inclination angle, confining pressure unloading rates, and initial confining pressure. However, there is a difference in the influence that each of these three affecting factors exerts upon these mechanical parameters. As can be seen from Figure 7(a), the peak 


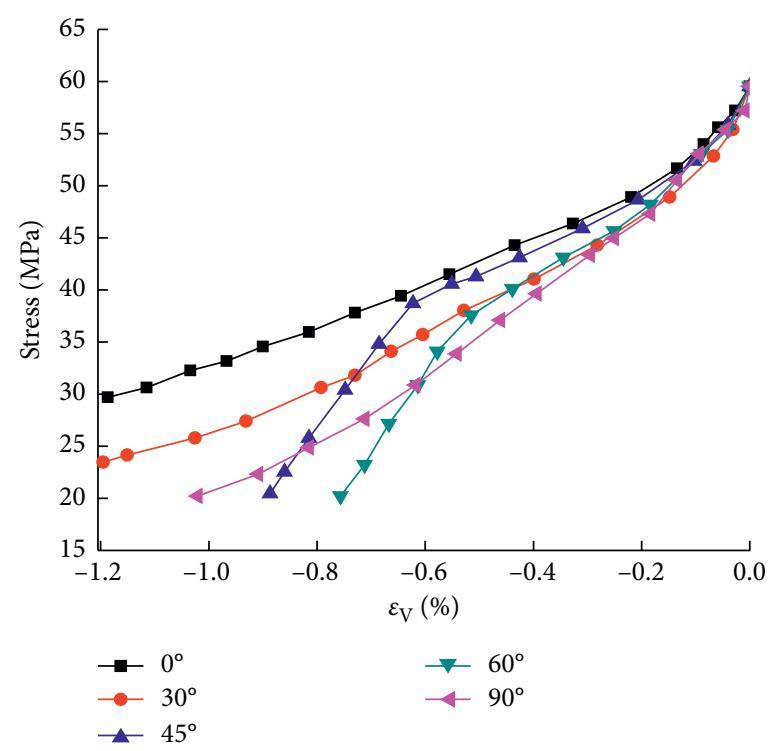

(a)

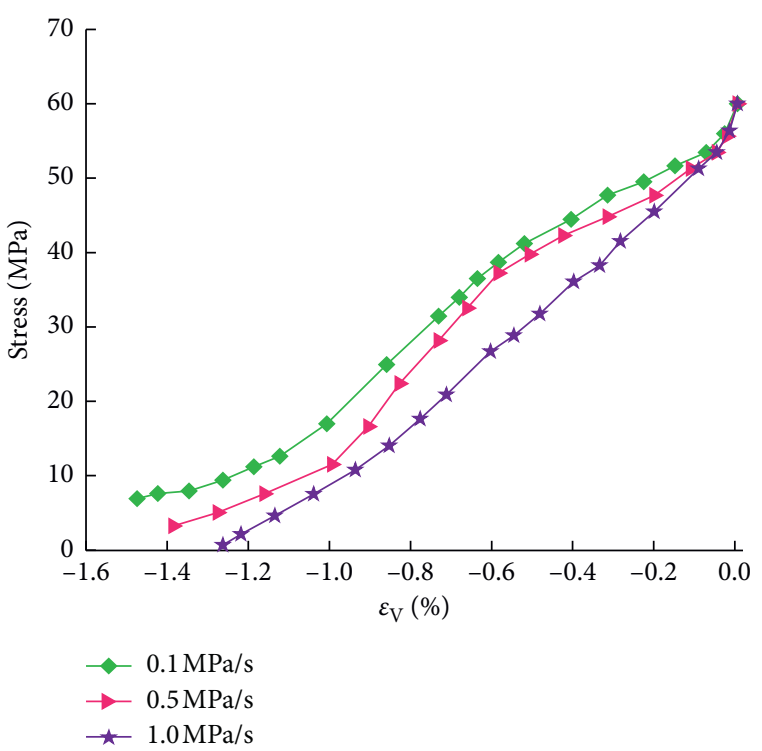

(b)

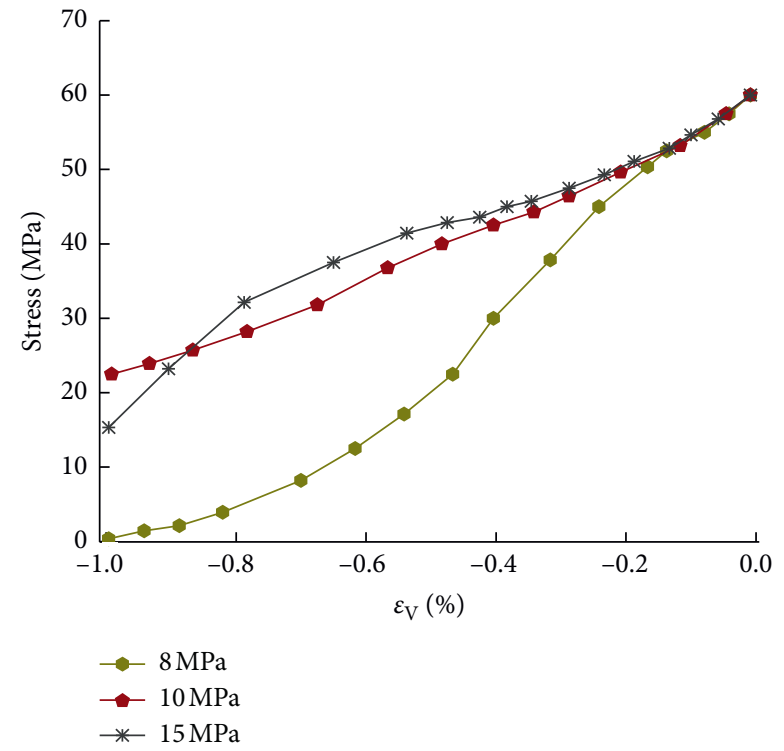

(c)

FIGURE 5: $\left(\sigma_{1}-\sigma_{3}\right)-\varepsilon_{v}$ curves of cracked specimens under axial unloading and radial unloading conditions. (a) Effect of crack angle. (b) Effect of unloading rate of confining pressure. (c) Effect of initial confining pressure.

strength of the specimens with $30^{\circ}$ crack dip angle was relatively smaller, and that of specimens with $90^{\circ} \mathrm{crack}$ dip angle was greater under axial unloading and radial unloading conditions. Compared with $30^{\circ}$ crack dip angle, peak strength of specimens with $30^{\circ}$ crack dip angle decreased by $7.94 \%$. When the fracture dip angle increased from 30 to 90 , the peak strength increased from $39.40 \mathrm{MPa}$ to $45.20 \mathrm{MPa}$, increase by $14.72 \%$.

Under the same crack dip angle and initial confining pressure (as shown in Figure 7(b)), the peak strength increased from $39.40 \mathrm{MPa}$ to $40.17 \mathrm{MPa}$, increasing by $1.95 \%$ when the confining pressure unloading rate increased from $0.1 \mathrm{MPa} / \mathrm{s}$ to $0.5 \mathrm{MPa} / \mathrm{s}$. When the confining pressure unloading rate increased from $0.5 \mathrm{MPa} / \mathrm{s}$ to
1.0 MPa/s, the peak strength increased from $40.17 \mathrm{MPa}$ to $42.32 \mathrm{MPa}$, increasing by $5.35 \%$. Under the condition of the same fracture dip angle and confining pressure unloading rate (as shown in Figure $7(\mathrm{c})$ ), the peak strength increased from $39.01 \mathrm{MPa}$ to $39.30 \mathrm{MPa}$ with the initial confining pressure increasing from $8 \mathrm{MPa}$ to $10 \mathrm{MPa}$, increasing by $0.74 \%$. When the initial confining pressure increased from $10 \mathrm{MPa}$ to $15 \mathrm{MPa}$, the peak strength increased from $39.30 \mathrm{MPa}$ to $42.32 \mathrm{MPa}$, increasing by $7.68 \%$. A comparative analysis of the above experimental results shows that the influence of crack inclination angle is the greatest, followed by that of the initial confining pressure, while the influence of the confining pressure unloading rate is relatively small. 


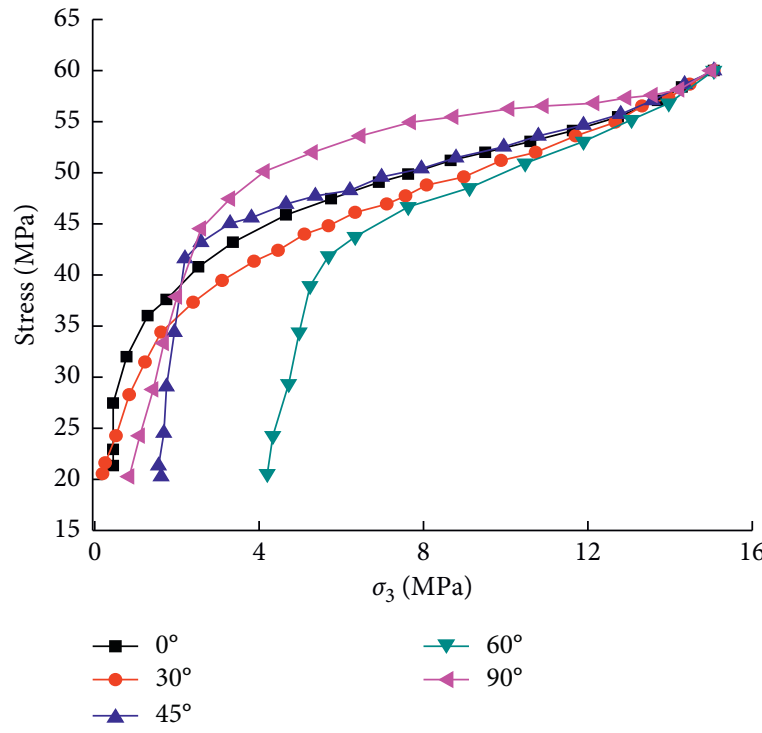

(a)

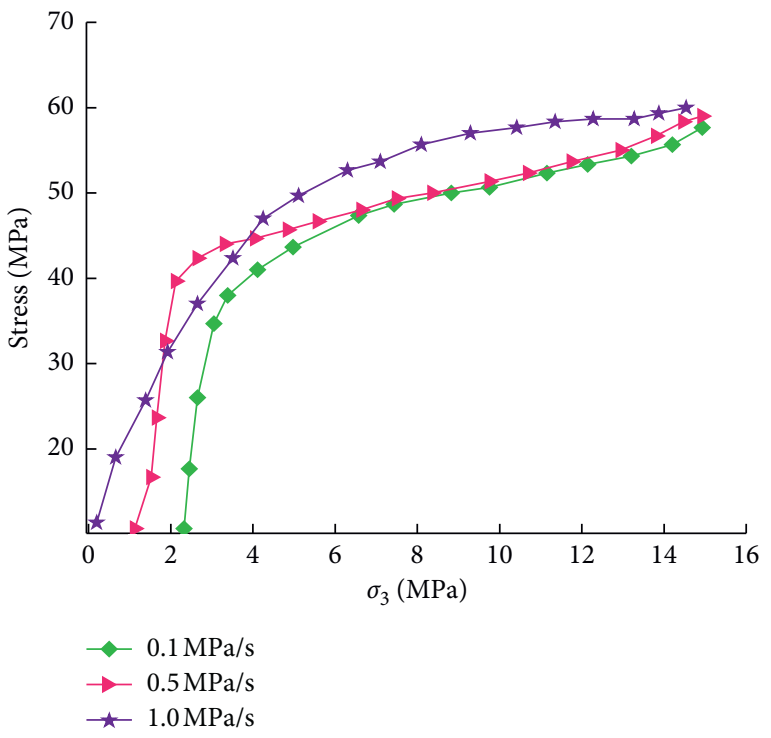

(b)

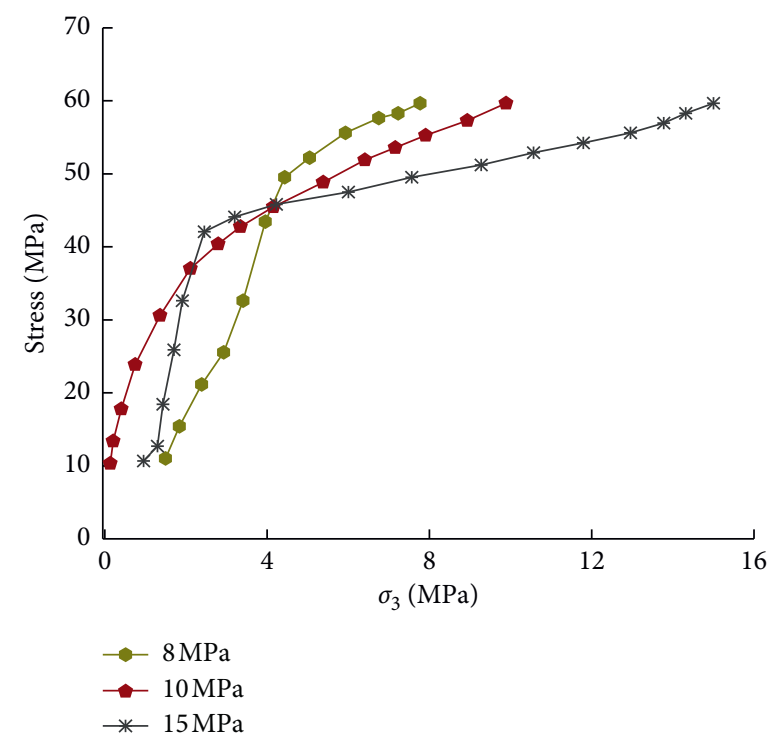

(c)

FiguRE 6: $\left(\sigma_{1}-\sigma_{3}\right)-\sigma_{3}$ curves of cracked specimens under axial unloading and radial unloading conditions. (a) Stress- $\sigma_{3}$. (b) Effect of unloading rate of confining pressure. (c) Effect of initial confining pressure.

\section{Energy Evolutions in the Process of Unloading}

Deformation and failure of rocks is essentially the result of mutual transformation of energy. Rocks are deformed under the action of external forces. Considering the deformation of a unit volume rock mass unit under the action of external force, and assuming that no heat exchange occurs with the external environment during the experiment, the total input energy generated by external force work is $U$, which can be obtained according to the first law of thermodynamics, as shown in Figure 8:

$$
U=U^{d}+U^{e}
$$

where $U^{e}$ is releasable elastic strain energy and $U^{d}$ is dissipated strain energy. Element dissipation energy $U^{d}$ is used to form the internal damage and plastic deformation of the element, and its change satisfies the first law of thermodynamics; i.e., the internal state changes conform to the trend of increasing entropy.

Energy dissipation is the essential property of rock deformation and failure; this reflects the process of continuous development of microdefects in rock, continuous weakening of strength, and eventual loss. Therefore, energy dissipation is directly related to damage and strength loss, and consumption reflects the attenuation degree of original strength. Since dissipated energy is used to form damage, the damage variable can be defined by energy. 


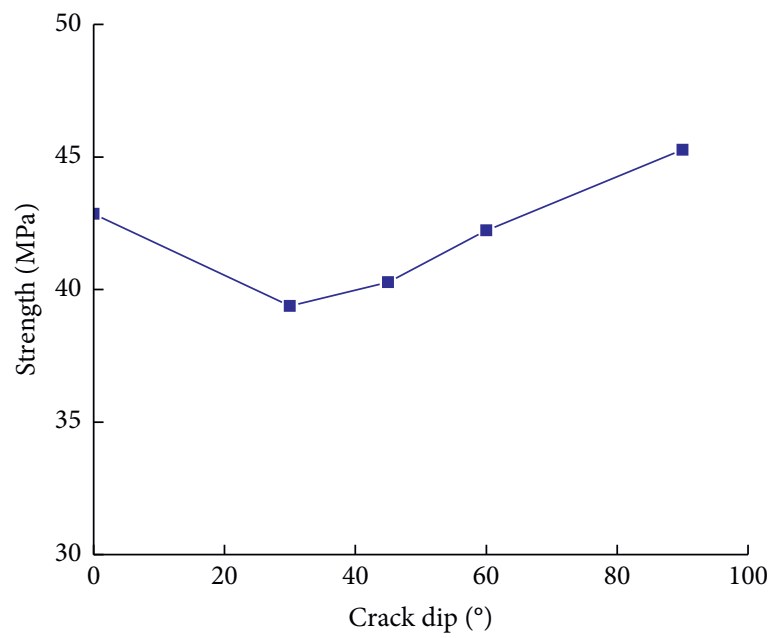

(a)

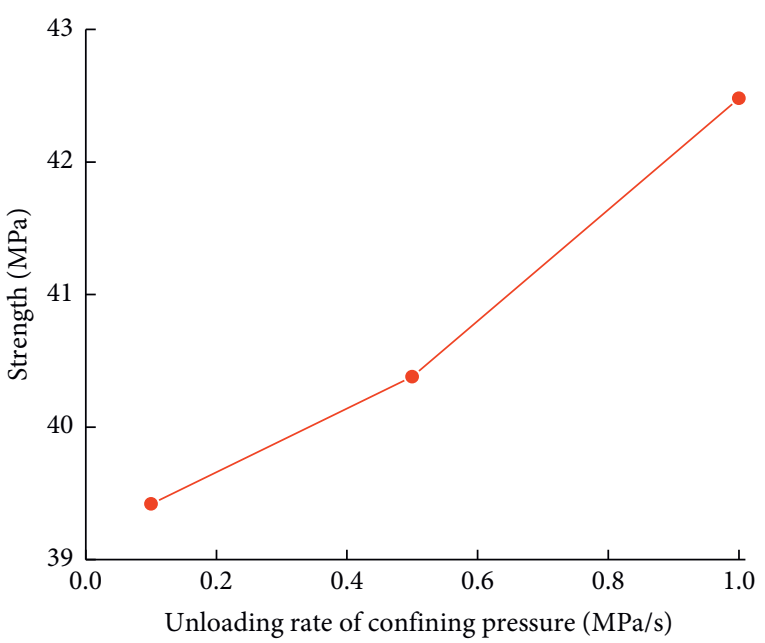

(b)

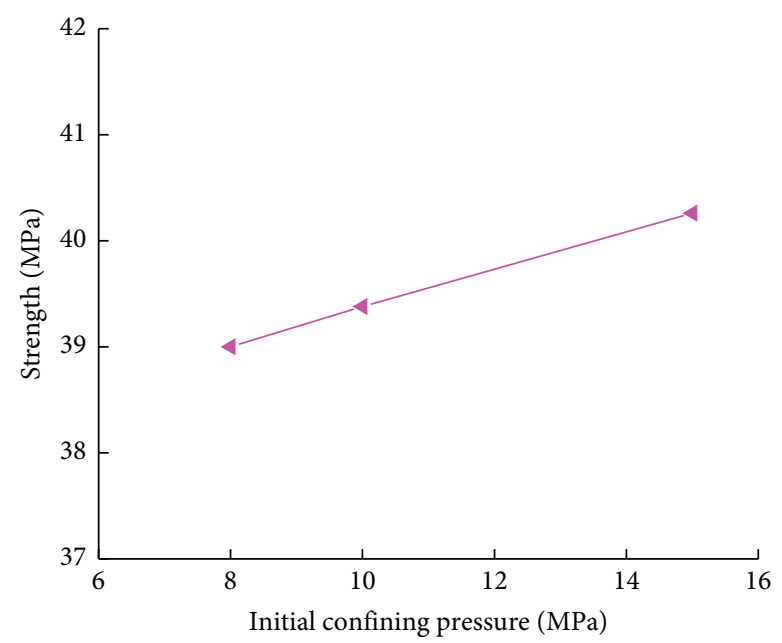

(c)

FIgURE 7: Peak strength of cracked specimens under axial unloading and radial unloading conditions. (a) Strength-crack dip. (b) Effect of unloading rate of confining pressure. (c) Effect of initial confining pressure.

The work done by the testing machine on the rock sample is the energy absorbed by the rock material during axial compression. However, the confining pressure also does work on the rock sample when the rock sample deforms under confining pressure. In the unloading test with confining pressure, the rock sample does work on the hydraulic oil in the triaxial pressure cylinder during circumferential expansion, so the energy actually absorbed by the rock material is smaller than the work done on the rock sample during axial compression of the testing machine. The energy $(K)$ actually absorbed by the rock sample in the triaxial test is as follows:

$$
K=\int \sigma_{1} \mathrm{~d} \varepsilon_{1}+2 \int \sigma_{3} \mathrm{~d} \varepsilon_{3},
$$

where $K$ refers to energy actually absorbed by the rock under the triaxial test, $\mathrm{MJ} / \mathrm{m}^{3} ; \varepsilon_{1}$ refers to axial deformation, \%; and $\varepsilon_{3}$ refers to lateral deformation, $\%$.

There is no external energy input during unloading under axial unloading and radial unloading paths, the elastic strain energy stored in the rock sample does work on the sample with the unloading of load, and the energy consumed by the rock sample is the area of axial stress and axial strain. According to the above analysis, the energy absorption and axial strain curves of sandstone during the whole failure process under axial unloading and radial unloading path are calculated, as shown in Figure 9.

Energy consumption is the deformation energy absorbed by the specimen during the damage process, which comprehensively reflects the effects of stress and unloading conditions. Therefore, it is used as damage variable to define that damage function not only has clear physical meaning, but also can reflect the influence of material nonlinearly on damage evolution law during deformation under three unloading conditions.

Due to the fact that there is no energy input from the outside under axial unloading and radial unloading paths, the energy forming the damage is part of elastic strain energy, and the energy consumed by the damage is the area of axial stress and axial strain curve of the sample before 
TABle 2: Test results of cracked specimens under different axial unloading and radial unloading paths.

\begin{tabular}{|c|c|c|c|c|c|c|c|}
\hline $\begin{array}{l}\text { Unloading } \\
\text { conditions }\end{array}$ & $\begin{array}{l}\text { Cracked } \\
\text { inclination } \\
\text { angle }\left(^{\circ}\right) \\
\end{array}$ & $\begin{array}{l}\text { Initial confining } \\
\text { pressure }(\mathrm{MPa})\end{array}$ & $\begin{array}{c}\text { Confining pressure } \\
\text { unloading rate } \\
(\mathrm{MPa} / \mathrm{s})\end{array}$ & $\begin{array}{c}\text { Axial pressure } \\
\text { unloading rate } \\
(\mathrm{mm} / \mathrm{min})\end{array}$ & $\begin{array}{l}\text { Strength } \\
(\mathrm{MPa})\end{array}$ & $\begin{array}{l}\text { Average of } \\
\text { strength } \\
(\mathrm{MPa})\end{array}$ & $\begin{array}{l}\text { Error } \\
\left(\mathrm{MPa}^{2}\right)\end{array}$ \\
\hline \multirow{9}{*}{$\begin{array}{l}\text { Axial unloading } \\
\text { and radial } \\
\text { unloading path }\end{array}$} & 0 & 15 & 0.5 & 0.1 & $\begin{array}{l}43.25 \\
44.07 \\
42.55 \\
41.33 \\
38.48\end{array}$ & 42.80 & 1.01 \\
\hline & 30 & 15 & 0.5 & 0.1 & $\begin{array}{l}38.48 \\
40.02 \\
40.88 \\
38.22\end{array}$ & 39.4 & 1.20 \\
\hline & 45 & 15 & 0.5 & 0.1 & $\begin{array}{l}41.29 \\
39.56 \\
38.76 \\
43.16\end{array}$ & 40.17 & 1.11 \\
\hline & 60 & 15 & 0.5 & 0.1 & $\begin{array}{l}42.31 \\
43.02 \\
40.11\end{array}$ & 42.15 & 1.49 \\
\hline & 90 & 15 & 0.5 & 0.1 & $\begin{array}{l}46.42 \\
44.28 \\
45.82 \\
44.28 \\
40.87\end{array}$ & 45.20 & 0.89 \\
\hline & 45 & 15 & 0.1 & 0.1 & $\begin{array}{l}39.64 \\
38.97 \\
38.12 \\
43.67\end{array}$ & 39.40 & 1.01 \\
\hline & 45 & 15 & 1.0 & 0.1 & $\begin{array}{l}42.85 \\
41.55 \\
41.21 \\
40.82\end{array}$ & 42.32 & 0.98 \\
\hline & 45 & 10 & 0.5 & 0.1 & $\begin{array}{l}39.56 \\
38.74 \\
38.08\end{array}$ & 39.30 & 1.05 \\
\hline & 45 & 8 & 0.5 & 0.1 & $\begin{array}{l}40.34 \\
39.76 \\
38.49 \\
37.45\end{array}$ & 39.01 & 1.26 \\
\hline
\end{tabular}

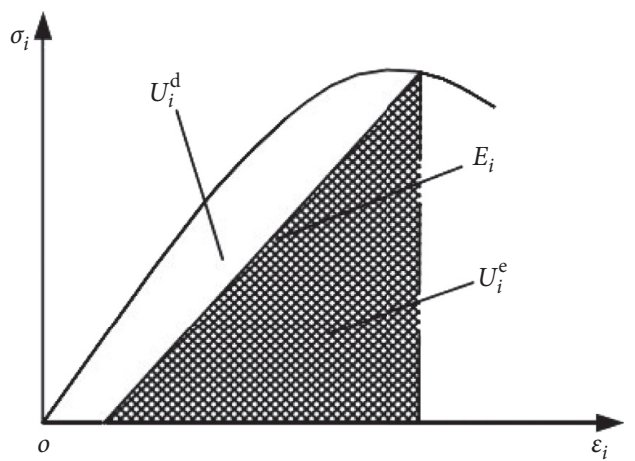

FIGURE 8: Quantitative relationship of energy release and energy dissipation.

failure. The calculation method of damage energy is shown in Figure 10. In Figure 10, $\Delta k_{i}$ is the energy consumed by specimen damage when axial deformation increases $\mathrm{d} \varepsilon_{1 i}, K_{s}$ is the total energy consumed by specimen damage, and it is the area of axial strain and axial stress before damage.

To calculate the energy consumed by damage of the sample under unloading condition, obtain the relation curve of energy consumed by damage of sandstone with axial strain before damage under unloading condition, as shown in Figure 11.

Damage variable $(D)$ can be expressed as

$$
D=\frac{\Delta k_{i}}{K_{S}}
$$

According to equation (4), the damage evolution process of sandstone can be obtained under axial unloading and radial unloading paths, as shown in Figure 12. Due to studying the damage development during unloading, the authors assumed that the initial damage $D_{0}$ of the specimen before unloading is 0 , and $D=1$ when the specimen is completely damaged. 


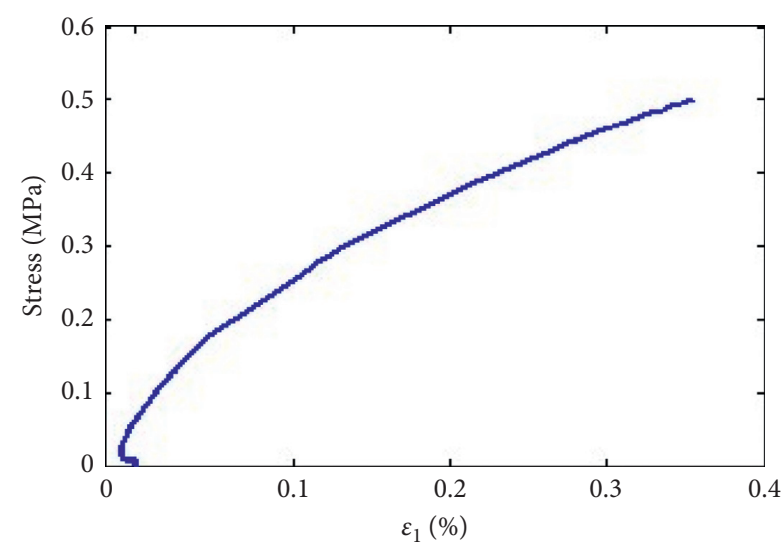

FIGURE 9: Energy characteristics of sandstone under axial unloading and radial unloading paths.

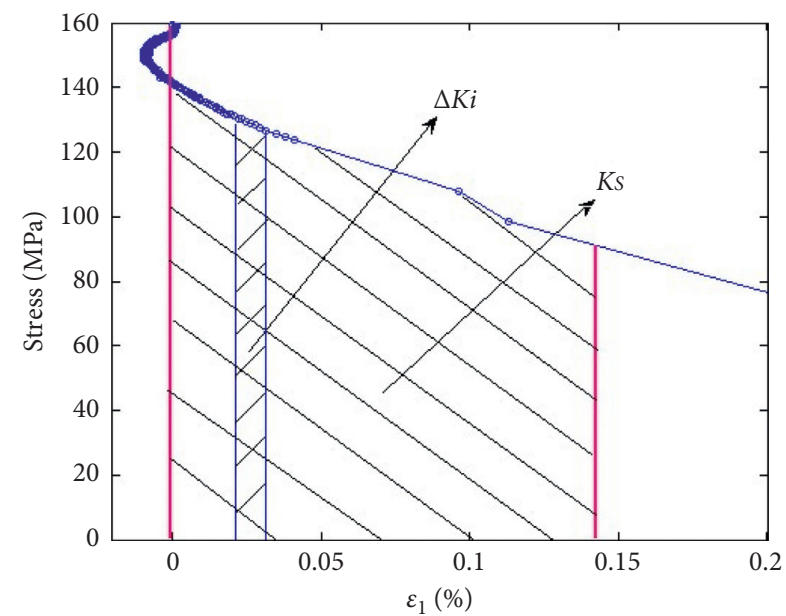

FIgURE 10: Schematic diagram of calculation $K_{s}$ under axial unloading and radial unloading paths.

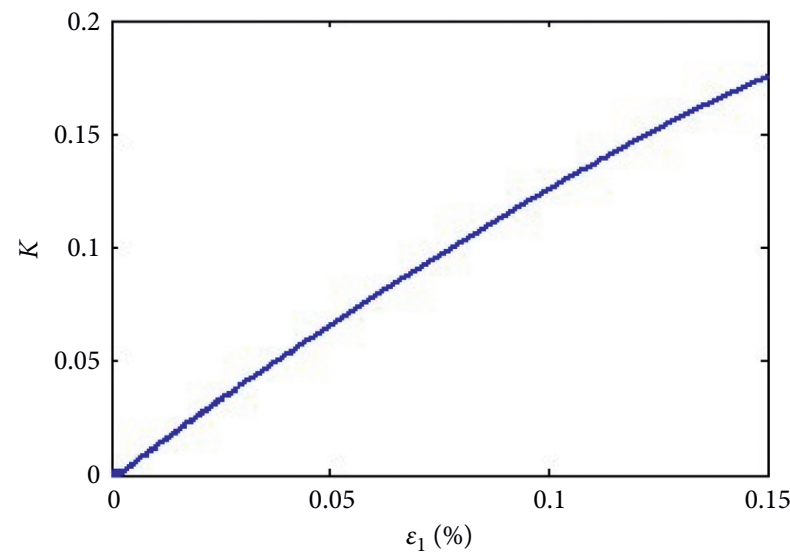

FIGURE 11: Curves of $K \sim \varepsilon_{1}$ of sandstone under axial unloading and radial unloading paths.

The regression analysis of the damage evolution process of sandstone was conducted under the condition of axial unloading and is shown in Figure 13.

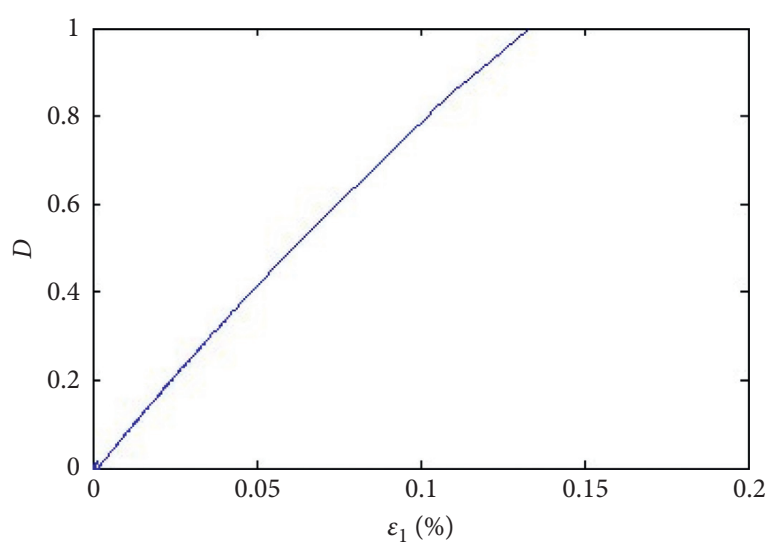

FIgURE 12: Curves of $D \sim \varepsilon_{1}$ of sandstone sample under axial unloading and radial unloading paths.

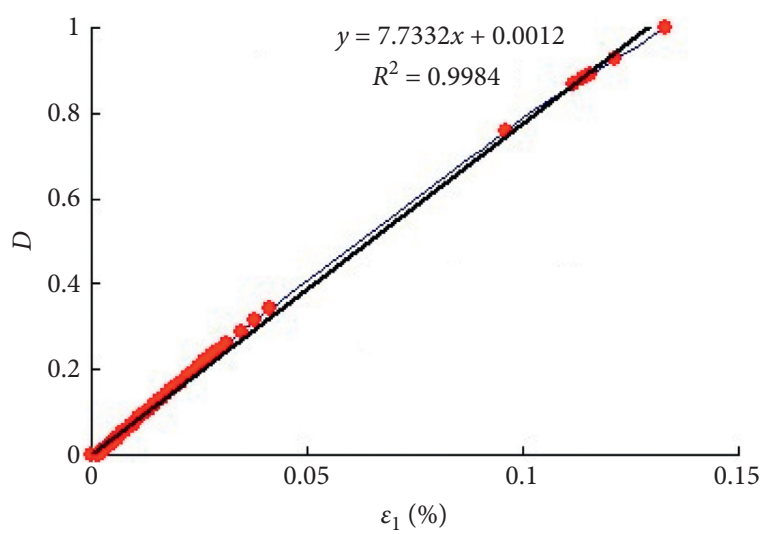

Figure 13: Damage of sandstone sample under axial unloading and radial unloading paths.

\section{Failure Characteristics and Its Mechanism}

The failure characteristics of cracked specimens are different under different unloading conditions. Damage to rock is caused by the tension effect from the mechanism of mesoscopic damage. The failure characteristics of rock often present shear failure under conventional triaxial compression tests from the macro view; however, rock often presents mixed tension-shear failure under axial unloading and radial unloading conditions.

This stress path, the axial unloading and radial unloading path, is equivalent to the maximum main stress $\left(\sigma_{1}\right)$ unloading and the minimum principal stress unloading. The minimum principal stress $\left(\sigma_{3}\right)$, unloaded, exerts an equivalent tensile stress along the opposite direction. Meanwhile, the maximum main stress $\left(\sigma_{1}\right)$ continues to be unloaded, which makes the Mohr's circle radius $\left(R=\left(\sigma_{1}-\sigma_{3}\right) / 2\right)$ increase slowly until the Mohr's circle is tangential to the Mohr-Coulomb curves. The cracked specimens happen as a result of brittle mixed tension-shear failure when the shear stress increases to the maximum level. The lateral strain of cracked specimens and the expansion capacity under the same stress level were greater than those of specimens under loading conditions when specimens were damaged. 


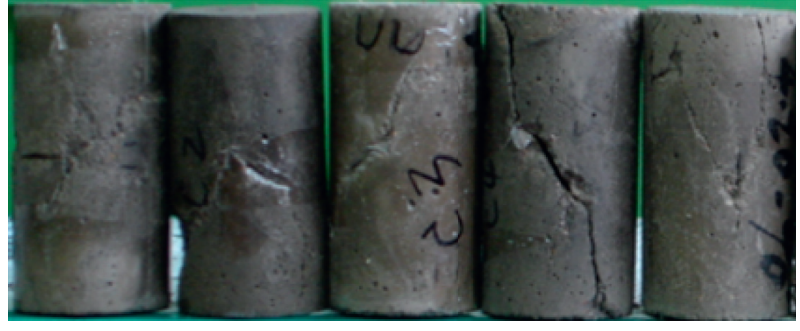

(a)
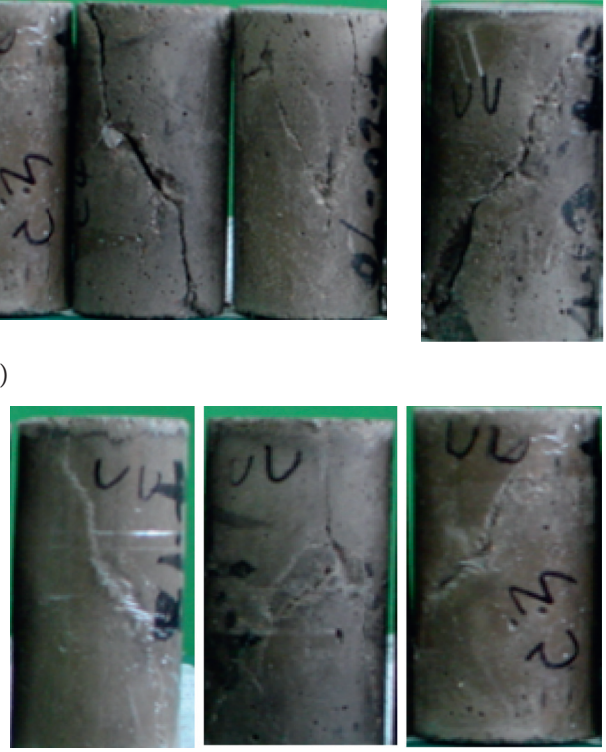

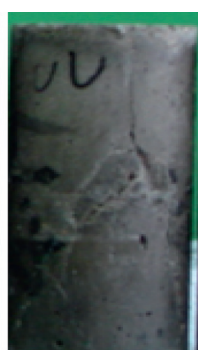

(c)

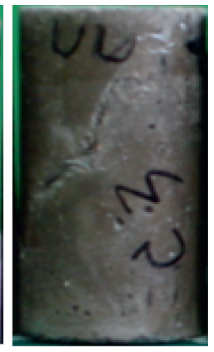

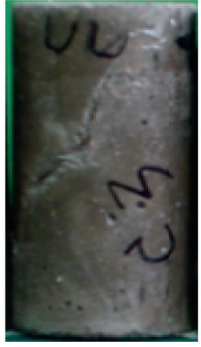

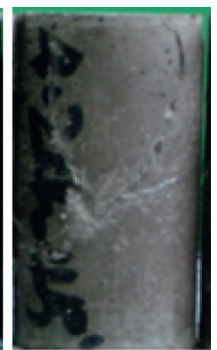

(b)

FigURE 14: Failure forms of cracked specimens under axial unloading and radial unloading conditions. (a) Effect of crack inclination angle: $0^{\circ}, 30^{\circ}, 45^{\circ}, 60^{\circ}, 90^{\circ}$, from left to right. (b) Effect of confining pressure unloading rate: $0.1 \mathrm{MPa} / \mathrm{s}, 0.5 \mathrm{MPa} / \mathrm{s}, 1.0 \mathrm{MPa} / \mathrm{s}$, from left to right. (c) Effect of initial confining pressure: $8 \mathrm{MPa}, 10 \mathrm{MPa}, 15 \mathrm{MPa}$, from left to right.

The failure characteristics of the specimens under axial unloading and radial unloading conditions are shown in Figure 14. As can be seen from Figure 14, the failure characteristic of cracked specimens under this path is mainly influenced by the crack inclination angle. At a crack inclination angle of $0^{\circ}$, the maximum principal stress and minimum principal stress had an inhibitory effect on the tensile stress of the crack tip in the loading process; this led to the high peak strength exhibited by the specimens. The crack occurred in the crack tip of specimens, and the angle between the crack and the direction of the maximum principal stress was roughly $15^{\circ}$. Finally, the failure characteristic of specimens is X-conjugate strike-slip failure.

At a crack inclination angle of $90^{\circ}$, although the cracks observed in specimens were parallel to the sources of maximum principal stress, the minimum principal stress had a strongly inhibitory effect on the crack. This in turn obviously increased the peak strength of the cracked specimen. These specimens exhibited tensile failures. The cracks occurred in the bottom of precracked specimens and went along with the precracked patterns to form the tension failure surfaces.

At crack inclination angles of $30^{\circ}, 45^{\circ}$, and $60^{\circ}$, the failure characteristics of specimens presented mixed tension-shear failures. The cracks originated from the crack tip of specimens, and the tension cracks were approximately parallel to the direction of the maximum principal stress. Finally, the tension cracks of specimens were cut through with the precracked surfaces.

The failure characteristics of cracked specimens often present mixed tension-shear failures under axial unloading and radial unloading conditions. The tensile failure was more obvious under axial unloading and radial unloading conditions than it was under the three stress paths in question: axial loading and constant confining pressure, axial loading and radial unloading, and constant axial pressure and radial unloading. The tensile cracking of specimens significantly increased and the failure mode almost presented tension-shear failure under constant axial pressure and radial unloading conditions. However, the degree to which tensile cracks developed was relatively small, and the failure characteristic was mixed tension-shear failure under axial loading and radial unloading conditions. The tensile failure was more obvious under axial unloading and radial unloading conditions, because the confining pressure exerted under unloading conditions is equivalent to exerting a tensile stress in the opposite direction; this in turn leads to a rapid increase in lateral deformation and the volumetric strain of the specimen which remains in a state of expansion. Finally, the tensile cracking of the specimens obviously increased.

\section{Conclusion}

(1) The mechanical properties of cracked specimens under axial unloading and radial unloading conditions are mainly influenced by crack inclination angle, confining pressure unloading rate, and initial confining pressure.

(2) Peak strength was not observed when the cracked specimens were damaged under axial unloading and radial unloading conditions, although the stress drop obviously occurred. To define the strength at which specimens were damaged, the inflection point of the $\left(\sigma_{1}-\sigma_{3}\right)-\sigma_{3}$ curves was defined as the damage 
point when the stress fell, and the stress of the inflection point was the peak strength.

(3) The peak strengths under axial unloading and radial unloading conditions are smaller than those under conventional triaxial compression conditions. The greater the confining pressure unloading rate or the greater the initial confining pressure level, the greater the peak strength of specimens under axial unloading and radial unloading conditions. However, the peak strength of specimens initially decreases and then increases with the continuous increase in the crack inclination angle. Furthermore, there is a difference in the influence these factors exert on the mechanical parameters; that is, the influence of the crack inclination angle is greatest, followed by that of the initial confining pressure, while that of the confining pressure unloading rate is relatively small.

(4) The failure characteristic of cracked specimens under axial unloading and radial unloading conditions is mainly influenced by crack inclination angle. The failure characteristic of rock often presents shear failure under the conventional triaxial compression test; however, under axial unloading and radial unloading paths, rock often presents a mixed tension-shear failure characteristic.

\section{Data Availability}

Most of the experimental data generated by this work are shown in the manuscript, and other data can be obtained from the corresponding author upon request.

\section{Conflicts of Interest}

The authors declare that they have no conflicts of interest.

\section{Acknowledgments}

The authors gratefully acknowledge the support of the National Natural Science Foundation of China (Nos. 11302167, 11572244, and 11872300).

\section{References}

[1] J. C. Jaeger, "Brittle fracture of rocks," in Proceedings of the Eighth Sympoium on Rock Mechanics, pp. 3-57, Baltimore, MD, USA, 1967.

[2] T. Shimamoto, "Confining pressure reduction experiments: a new method for measuring frictional strength over a wide range of normal stress," International Journal of Rock Mechanics and Mining Sciences \& Geomechanics Abstracts, vol. 22, no. 4, pp. 227-236, 1985.

[3] F. Gao, K.-p. Zhou, X.-w. Luo, and J.-b. Zhai, "Effect of induction unloading on weakening of rock mechanics properties," Transactions of Nonferrous Metals Society of China, vol. 22, no. 2, pp. 419-424, 2012.

[4] J.-h. Hu, T. Lei, K.-p. Zhou, X.-w. Luo, and N.-g. Yang, "Mechanical response of roof rock mass unloading during continuous mining process in underground mine,"
Transactions of Nonferrous Metals Society of China, vol. 21, no. 12, pp. 2727-2733, 2011.

[5] J. S. O. Lau and N. A. Chandler, "Innovative laboratory testing," International Journal of Rock Mechanics and Mining Sciences, vol. 41, no. 8, pp. 1427-1445, 2004.

[6] J. A. Hudson, S. L. Crouch, and C. Fairhurst, "Soft, stiff and servo-controlled testing machine: a review with reference to rock failure," Engineering Geology, vol. 6, no. 3, pp. 155-189, 1972.

[7] C. D. Martin, The strength of massive Lac du Bonnet granite around underground opening, University of Manitoba, Winnipeg, Canada, 1993.

[8] S. R. Swanson and W. S. Brown, "An observation of loading path independence of fracture in rock," International Journal of Rock Mechanics and Mining Sciences \& Geomechanics Abstracts, vol. 8, no. 3, pp. 277-278, 1971.

[9] S. L. Crouch, "A note on post-failure stress-strain path dependence in norite," International Journal of Rock Mechanics and Mining Sciences \& Geomechanics Abstracts, vol. 9, no. 2, pp. 197-204, 1972.

[10] Y. S. Wu and J. D. Li, "Unloading properties of marble," Chinese Rock and Soil Mechanics, vol. 5, no. 1, pp. 29-36, 1984.

[11] S. Wang, X. Li, J. Yao et al., "Experimental investigation of rock breakage by a conical pick and its application to nonexplosive mechanized mining in deep hard rock," International Journal of Rock Mechanics and Mining Sciences, vol. 122, p. 104063, 2019.

[12] S. Wang, L. Huang, and X. Li, "Analysis of rockburst triggered by hard rock fragmentation using a conical pick under high uniaxial stress," Tunnelling and Underground Space Technology, vol. 96, p. 103195, 2020.

[13] K. Du, C. Yang, R. Su, M. Tao, and S. Wang, "Failure properties of cubic granite, marble, and sandstone specimens under true triaxial stress," International Journal of Rock Mechanics and Mining Sciences, vol. 130, p. 104309, 2020.

[14] Q.-B. Meng, C.-K. Wang, J.-F. Liu, M.-W. Zhang, M.-M. Lu, and $\mathrm{Y} . \mathrm{Wu}$, "Physical and micro-structural characteristics of limestone after high temperature exposure," Bulletin of Engineering Geology and the Environment, vol. 79, no. 3, pp. 1259-1274, 2020.

[15] Q. B. Meng, W. Qian, J. F. Liu, M. W. Zhang, M. M. Lu, and $\mathrm{Y}$. Wu, "Analysis of triaxial compression deformation and strength characteristics of limestone after high temperature," Arabian Journal of Geosciences, vol. 13, no. 153, 2020.

[16] T. B. Li and L. S. Wang, "An experimental study on the deformation and failure features of a basalt under unloading condition," Chinese Journal of Rock Mechanics and Engineering, vol. 12, no. 4, pp. 20-27, 1993.

[17] Y. Chen, X. X. Yao, and N. G. Geng, "Stress path, strength and dilatancy of rocks," Science China: Mathematics, vol. 23, no. 4, pp. 492-501, 1980.

[18] P. K. Kaiser, S. Yazici, and S. Maloney, "Mining-induced stress change and consequences of stress path on excavation stability-a case study," International Journal of Rock Mechanics and Mining Sciences, vol. 38, no. 2, pp. 167-180, 2001.

[19] F. Wu, T. Liu, J. Liu, and X. Tang, "Excavation unloading destruction phenomena in rock dam foundations," Bulletin of Engineering Geology and the Environment, vol. 68, no. 2, pp. 257-262, 2009.

[20] M. Q. You and A. Z. Hua, "Effect of stress path on strength and deformation of specimen," Chinese Journal of Geotechnical Engineering, vol. 20, no. 5, pp. 101-104, 1998.

[21] A. Taheri and K. Tani, "Use of down-hole triaxial apparatus to estimate the mechanical properties of heterogeneous 
mudstone," International Journal of Rock Mechanics and Mining Sciences, vol. 45, no. 8, pp. 1390-1402, 2008.

[22] A. G. Corkum and C. D. Martin, "The mechanical behaviour of weak mudstone (Opalinus Clay) at low stresses," International Journal of Rock Mechanics and Mining Sciences, vol. 44, no. 2, pp. 196-209, 2007.

[23] L. S. Tsai, Y. M. Hsieh, M. C. Weng, T. H. Huang, and F. S. Jeng, "Time-dependent deformation behaviors of weak sandstones," International Journal of Rock Mechanics and Mining Sciences, vol. 45, no. 2, pp. 144-154, 2008.

[24] A.-Z. Hua and M.-Q. You, "Rock failure due to energy release during unloading and application to underground rock burst control," Tunnelling and Underground Space Technology, vol. 16, no. 3, pp. 241-246, 2001.

[25] H. Z. Li, C. C. Xia, and W. M. Xiao, "Research on constitutive model of marble of jinping hydropower station under loading and unloading conditions," Chinese Journal of Rock Mechanics and Engineering, vol. 29, no. 7, pp. 1498-1495, 2010.

[26] J. N. Guo, J. F. Liu, Q. Li et al., "Variation law of coal permeability under cyclic loading and unloading," Thermal Science, vol. 23, no. 3b, pp. 1-8, 2019.

[27] E. Gaziev, "Rupture energy evaluation for brittle materials," International Journal of Solids and Structures, vol. 38, no. 4243, pp. 7681-7690, 2001.

[28] E. Gaziev and V. Levtchouk, "Strength characterization for rock under multiaxial stress states," in Proceedings of the 9th International Congress on Rock Mechanics, Paris, France, August 1999.

[29] M. Cai and H. Horii, "A constitutive model of highly jointed rock masses," Mechanics of Materials, vol. 13, no. 3, pp. 217-246, 1992.

[30] M. Cai and P. K. Kaiser, "Assessment of excavation damaged zone using a micromechanics model," Tunnelling and Underground Space Technology, vol. 20, no. 4, pp. 301-310, 2005.

[31] G. Wu and L. Zhang, "Studying unloading failure characteristics of A rock mass using the disturbed state concept," International Journal of Rock Mechanics and Mining Sciences, vol. 41, no. 3, pp. 419-425, 2004.

[32] M. F. Ashby and C. G. Sammis, "The damage mechanics of brittle solids in compression," Pure and Applied Geophysics PAGEOPH, vol. 133, no. 3, pp. 489-521, 1990.

[33] H. S. Bhat, C. G. Sammis, and A. J. Rosakis, "The micromechanics of westerley granite at large compressive loads," Pure and Applied Geophysics, vol. 168, no. 12, pp. 2181-2198, 2011.

[34] E. Hoek and Z. T. Bieniawski, "Brittle fracture Propagation in rock under compression," International Journal of Fracture Mechanics, vol. 1, no. 3, pp. 137-155, 1965.

[35] O. Reyes and H. H. Einstein, "Fracture mechanism of fracture rock, a fracture coalescence model," in Proceedings of the 7th ISRM Congress, pp. 333-340, Aachen, Germany, September 1991.

[36] R. C. Nolen-Hook and R. B. Gordon, "Optical detection of crack patterns in the opening-mode fracture of marble," International Journal of Rock Mechanics and Mining Sciences \& Geomechanics Abstracts, vol. 24, no. 4, pp. 135-144, 1987.

[37] H. H. James, N. B. Tulio, and R. I. Anthony, "Three-dimensional influence coefficient method for cohesive crack simulations," Engineering Fracture Mechanics, vol. 71, no. 15, pp. 2109-2124, 2004.

[38] T. L. Han, Y. S. Chen, and J. P. Shi, "Experimental study of effect of stress paths on mechanical characteristics of cracked samples," Chinese Journal of Rock Mechanics and Engineering, vol. 32, pp. 3092-3099, 2013. 